\title{
WHY BEING BORED MIGHT NOT BE A BAD THING AFTER ALL
}

\author{
GUIHYUN PARK ${ }^{1}$ \\ The Australian National University
}

BENG-CHONG LIM

Nanyang Technological University Singapore

\author{
HUI SI OH \\ Singapore Management University
}

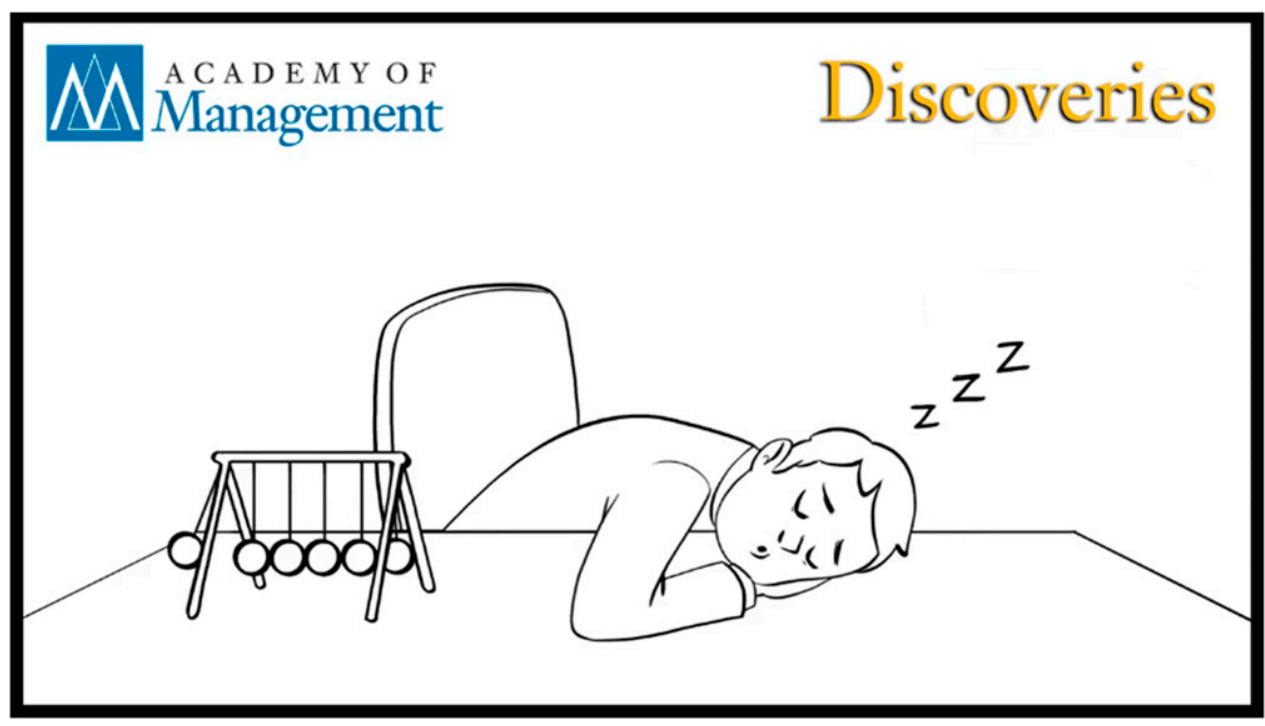

Boredom is likely one of the most prevalent, yet least understood, emotions. It is easy to find examples of how boredom can engender other negative emotional states that often lead to somewhat negative-albeit unintended-outcomes (e.g., risky or delinquent behaviors). But does boredom invariably lead to negative consequences? Could being bored also have less obvious effects, such as increased creativity? We explore the consequences of being bored using three experimental studies that manipulate boredom and identify the benefits for creativity of being bored. In Study 1, we found that boredom helped boost individual productivity on an idea-generation task. In Study 2 , we showed that the boredom manipulation only increased boredom and not other negative activating emotions (i.e., anger and frustration), thus highlighting boredom's unique effect on creativity. In Study 3, we found that boredom did not universally increase creativity for a product development task; instead, only those individuals with a high learning goal orientation (LGO), high need for cognition (NOC), high openness to experience, and high internal locus of control (LOC) showed a significant increase in creativity when feeling bored. These counterintuitive findings offer an empirical basis and theoretical motivation for viewing boredom as a variety-driving emotion that motivates individuals to engage in novelty-seeking responses-i.e., engaging in different, often unusual, ways of doing things that are unlike typical or predictable responses. Building on our findings, we discuss how organizations can use this untapped resource to motivate employees for positive outcomes.

\footnotetext{
${ }^{1}$ Corresponding author.
}

How often do you hear someone at home or work lament that they're bored? Getting stuck in traffic, waiting in line to pay for a purchase, listening to a monotonous lecture, or enduring a long meeting: 
Boredom is typically an unavoidable reaction to such highly repetitive and often understimulating daily routines. Csikszentmihalyi (1975) argues that individuals feel bored much more frequently than anxious when working on various tasks. People often search for ways to reduce their sense of boredom-for instance, by doodling on meeting notes, pondering what they will have for dinner, playing with their fingernails, staring out the window, or even administering electrical shocks to themselves (Wilson et al., 2014). Although people may view boredom negatively, they also see it as something they need to put up with-for instance, filling out a lengthy application form to apply for a coveted job or, as a new employee, completing boring tasks to advance to more interesting work. However, a number of researchers (Conrad, 1997; Csikszentmihalyi, 1975; Fisher, 1993) assert that the effects of boredom are nontrivial, and therefore, it is paramount that we deepen our understanding of boredom and its effects.

Earlier theories of work motivation discussed the critical role of boredom in individuals' motivation and engagement with their work. For example, boredom has been framed as an aspect of job characteristics theory, by which individuals report unfulfilled needs for achievement and view their work as lacking in significant meaning (Hackman \& Oldham, 1976). Also, in Beyond Boredom and Anxiety, Csikszentmihalyi (1975) argues that individuals with a high skill level feel bored and unchallenged when they are assigned less complex tasks. One way to experience what Csíkszentmihályi terms flow in one's work is to modify the task environment such that the task is not boring, but instead becomes engaging. Also, despite its seemingly innocuous nature, boredom can cause serious consequences, especially in jobs in which a single mistake can put many lives at risk. In their study of U.S. Air Force military personnel, Charlton and Hertz (1989) found that camp guards were willing to risk severe penalties, and even their jobs, to engage in various rulebreaking activities on a regular basis, as long as these activities could ease their boredom. Boredom was one of the main reasons the U.S. Air Force had great difficulty recruiting and retaining pilots for unmanned aerial vehicles: Many pilots confessed that they would rather risk their lives by fighting in a real battle than feel "grounded" while doing boring tasks (Cummings, Mastracchio, Thornburg, \& Mkrtchyan, 2013; The Economist, 2014).

Despite being one of the most critical emotions considered in early work motivation theories, boredom, as an emotion, has not been actively discussed or investigated in organizational science. Even with the increase in the number of studies on emotions over the last two decades, only a handful have explored the nature of boredom; searches on the web portal for American Psychological Association journals reveal that fewer than 40 such studies have been published since 1930. Compared with other well-researched emotions, such as happiness, anger, and anxiety, boredom is remarkably understudied, given its relatively frequent occurrence in daily life (Nett, Goetz, \& Daniels, 2010). Pekrun, Goetz, Daniels, Stupnisky, and Perry (2010) may be spot-on to call boredom the "silent" emotion because it has largely been neglected in psychological research.

\section{THE PSYCHOLOGY OF BOREDOM}

Boredom is defined as an affective state composed of unpleasant feelings when an individual feels a lack of stimulation and experiences difficulty concentrating on the current activity (Fisher, 1993). Boredom involves relatively low arousal; that is, bored individuals do not feel highly aroused and are uninterested at a given moment. However, low arousal does not automatically lead to one's feeling bored. For example, individuals who are meditating feel calm and relaxed in a low-arousal state (Mikulas \& Vodanovich, 1993). Apart from low arousal, boredom is also associated with a state of dissatisfaction or displeasure. Physical and psychological symptoms of boredom include leaning the head back, yawning, and decreased movement (Wallbott, 1998). Brissett and Snow (1993) found that people who experienced boredom reported extended time perception-i.e., the absence of momentum or flow of time, during which they felt that their lives came to a standstill. Bored individuals often report restlessness, whereby they wish they could be doing something else (Guglielmi, Simbula, Mazzetti, Tabanelli, \& Bonfiglioli, 2013), or state that they feel trapped in an unfulfilling situation, have difficulty concentrating on the current activity, or feel guilty about wasting time (Martin, Sadlo, \& Stew, 2006). Thus, boredom is an aversive feeling that motivates individuals to change the status quo, either by shifting out of the activity or leaving the situation.

\section{Previous Studies of Boredom}

In studies that have examined the effects of boredom, the primary focus has been on its disruptive and harmful consequences. For example, in his book on the causes of evil, Baumeister (1999) argues that

Author's voice:

What motivated you to undertake this research? 
feeling bored is one of the main causes of violence, as it facilitates thrill-seeking and risk-taking behaviors (see also Baumeister \& Campbell, 1999); individuals engage in aggressive and violent behaviors as a way of generating excitement. Shoplifters identified boredom as the main cause of their behavior because shoplifting provided arousal and enjoyment to ease their boredom (Katz, 1988). Individuals also reported that boredom was the main reason they engaged in deviant behaviors, such as physical and verbal aggression toward others (Joireman, Anderson, \& Strathman, 2003), and individuals who reported frequently feeling bored at work were also more likely to engage in sabotage and deviant behaviors (Fisher, 1993). Job-related boredom has been positively related to alcohol consumption and work stress (Wiesner, Windle, \& Freeman, 2005), and bored employees were found to be more likely to be absent from work and/or leave the organization (Kass, Vodanovich, \& Callender, 2001; Van Hooff \& van Hooft, 2017).

Although previous research has highlighted the negative consequences of boredom, can good outcomes also arise from being bored? Anecdotal evidence suggests that feeling bored may not be all bad. For instance, Csikszentmihalyi (1975) describes boredom as a precedent for ingenious ideas and creativity and cites Issac Newton, who formulated his major discoveries in the course of the 2 years he spent feeling bored during a country retreat after college. In addition, Galileo was drawn to conduct dangerous experiments in search of the center of gravity, despite having been professionally trained in medicine. Lewin (1951) argues that boredom triggers curiosity in individuals and facilitates learning and the exploration of new ideas, and Suedfeld (1975) posits that boredom is not always a negative and counterproductive emotion, and can be viewed as a potential source of balance and creativity. Schultz (1964) also suggests that boredom is a form of variety drive, by which continuous exposure to the same rewarding stimuli actually increases, instead of decreasing, individuals' willingness to take on and explore alternative stimuli. Accordingly, boredom could motivate individuals to exhibit an array of behaviors that seek challenges or stimulation in a positive manner (Farmer \& Sundberg, 1986).

If we can view boredom in a different light-specifically, as capable of triggering both positive and negative outcomes-perhaps we can advance our research

Author's voice: How did the paper evolve as you worked on it? efforts to better understand when and why experiencing boredom can lead to different outcomes for different people in different contexts. Doing so may motivate more research interest in this largely unexplored domain and advance theoretical development with the aim of reconciling inconsistent findings in the literature. Specifically, could bored employees channel their attention into experimenting with new ideas and advancing innovation? Who might benefit more from being bored, and why? Such questions remain unanswered because so little research has been conducted on boredom. Moreover, research on boredom has relied almost exclusively on correlational methods, in which boredom and associated behaviors are often measured concurrently; few studies have experimentally manipulated boredom and measured its effects (Sansone, Weir, Harpster, \& Morgan, 1992; Van Tilburg \& Igou, 2011). This poses serious limitations in interpreting the effects of boredom because it is likely that boredom co-occurs with other strongly negative emotions, such as anger and frustration. For example, an employee who has been relegated to unchallenging tasks because of unfair work assignments is likely to not only feel bored, but angry, and frustrated as well.

To provide preliminary insights into the relationship between boredom and creativity, we conducted three separate, but related, experimental studies using two creativity tasks. In Study 1, participants engaged in an idea-generation task in which they generated excuses for being late for work. In Study 2, we further tested whether our boredom manipulation distinctively elicited boredom and not other activating negative emotions, such as anger and frustration. In Study 3, participants were instructed to come up with creative ideas related to a product for pets. To explore the phenomenon further, we also measured various individual differences, such as Big Five personality traits and goal orientation, to examine moderation-of-process and delve deeper into the mechanisms involved in the boredom-creativity link.

Testing the boredom-creativity link also answers a call from the field of mood-creativity literature. Emotion as a pivotal role in human cognitive processes has long been studied as the main predictor of creativity (George \& Zhou, 2002; Isen \& Baron, 1991). Despite the robust and positive link between positive affective states and creativity $(r=0.12)$, a metaanalysis of negative affective states and creativity found heterogeneous, nonsignificant, and overall negative effects ( $r=-0.03$; Baas, De Dreu, \& Nijstad, 2008). Further compounding the problem, experimental studies on negative mood and creativity showed a positive and nonsignificant effect $(r=$ 0.03), whereas correlational studies showed a 
negative and significant effect $(r=-0.08$; Baas et al., 2008). In addition, most studies focused on negative activating emotions such as fear and anxiety, which make it difficult for the mechanism to generalize across different negative emotions. Negative emotions are often distinctive in their behavioral responses, so it may not be appropriate to assume that all negative moods relate to creativity through a common mechanism. Baas et al. (2008) also highlight the need for experimental studies that focus on a specific emotion-creativity link.

\section{STUDY 1}

\section{Method}

Participants. One hundred one undergraduate college students (52 in the experimental condition and 49 in the control condition) from a large university in Singapore (59 percent female; age range = 18-25; Chinese ethnicity $=86$ percent) took part in the study.

Procedure. On arrival in the laboratory, participants were seated in individual cubicles and told they would be engaging in two ostensibly unrelated tasks that were randomly selected from a pool of tasks. For the first task, participants were told they would be working on a color perception task that involved a bowl of green and red beans. Participants in the boredom condition were asked to sort the beans by color for 30 minutes. Specifically, participants were given a large bowl of beans in two colors (green and red) and an empty bowl. The experimenter then told participants to use only one hand to sort the beans. They were also told to sort the beans one at a time. These rules were imposed to create a monotonous activity to increase boredom (Geiwitz, 1966). Participants in the control condition were asked to work on an art project using paper, beans, and glue for 30 minutes. After performing the bean task, participants were informed that they would be taking part in an idea-generation task for the next 5 minutes. Specifically, they were asked to imagine a hypothetical situation in which Person A is 2 hours late for a work meeting and to list all of the feasible and justifiable reasons Person A could use to account for being late so that Person A would not be perceived negatively by his teammates. Participants were told there were no right or wrong responses and encouraged to generate as many ideas as possible.

Author's voice:

What was the most difficult or challenging aspect of this research project?

\section{Measures}

Boredom manipulation check. Right after the bean task, one item of boredom ("bored") was measured on a 7-point Likert scale, along with positive and negative mood items. Individuals in the boredom condition reported a significantly higher level of boredom $(M=5.13$, standard deviation $=1.62)$ than individuals in the control condition $(M=3.24$, $\mathrm{SD}=1.41)(t(99)=6.24, p<.01)$.

Negative and positive mood. Right after the bean task, negative and positive mood were measured with the Positive and Negative Affect Scale (PANAS; Watson, Clark, \& Tellegen, 1988). Reliabilities were acceptable (positive activating affect, $\alpha=0.82$; negative activating affect, $\alpha=0.94$ ).

Uniqueness of ideas. Following the approach of De Dreu, Baas, and Nijstad (2008), the creativity of individuals' ideas was measured using a 5-point Likert scale ranging from 1 (Not unique at all) to 5 (Extremely unique). Two independent coders were asked to rate the ideas based on uniqueness $\left(r_{\mathrm{wg}}=\right.$ $0.88 ; \alpha=0.81 ; \mathrm{ICC}_{1}=0.59 ; \mathrm{ICC}_{2}=0.73$ ).

Number of ideas. The number of ideas each individual generated was counted at the end of the 5-minute idea-generation task.

\section{Results}

Table 1 presents the descriptive statistics for and correlations of the main variables in Study 1. We tested the effect of the boredom condition on individuals' idea-generation performance. Individuals in the boredom condition produced a greater number of ideas $(M=15.64, \mathrm{SD}=7.57)$ than individuals in the control condition $(M=12.70, \mathrm{SD}=6.39), t(99)=$ 2.08, $p<.05$. Also, individuals in the boredom condition produced ideas that were judged to be more unique $(M=4.06, \mathrm{SD}=1.29)$ than individuals in the control condition $(M=3.56, \mathrm{SD}=1.24)$, $t(99)=2.00, p<.05$. Therefore, boredom significantly increased both the number of ideas generated and their uniqueness. We also ran a hierarchical

TABLE 1

Descriptive Statistics and Correlations for Main Variables (Study 1)

\begin{tabular}{lrrcrrr}
\hline & M & SD & 1 & $\mathbf{2}$ & $\mathbf{3}$ & $\mathbf{4}$ \\
\hline 1. Boredom condition $^{\mathrm{a}}$ & .51 & .50 & & & & \\
2. Number of ideas & 14.22 & 7.14 & $.21^{*}$ & & & \\
3. Uniqueness of ideas & 3.82 & 1.28 & $.19^{*}$ & $.49^{* *}$ & & \\
4. Negative mood & 1.59 & .68 & .16 & .11 & -.08 & \\
5. Positive mood & 2.85 & 1.38 & $-.33^{* *}$ & .19 & .03 & .02
\end{tabular}

${ }^{\text {a }} \mathbf{0}=$ control, $1=$ boredom

${ }^{*} p<.05$

${ }^{* *} p<.01$ 
regression analysis to test the significance of the effects of boredom on individual performance on the idea-generation task. Table 2 (Model 2) shows that the effect of the boredom condition on the number of ideas generated remained significant even after controlling for the effects of positive mood and negative mood $(\beta=0.28, p<.01)$. Table 3 (Model 2 ) shows that the boredom condition positively and significantly predicted the uniqueness of ideas that individuals generated $(\beta=0.26, p<.05)$ after controlling for the effects of positive and negative mood.

\section{STUDY 2}

Study 1 revealed that feeling bored is actually beneficial for creativity. A related question would be whether other emotions are inadvertently involved in the process. That is, if the task also induced a significant amount of anger, it might serve to increase creativity if angry individuals pushed themselves harder and produced more ideas (Chong \& Park, 2017; Van Kleef, Anastasopoulou, \& Nijstad, 2010). In a similar vein, the dual-pathway model of moodcreativity argues that feelings of anger and frustration can facilitate creativity through a perseverance and effort-driven mechanism (Baas et al., 2008). More critically, in organizational settings, boredom is likely to be mixed with other negative emotions, such as frustration and anger. Previous studies on boredom have focused on correlational design, which lacks precision in examining the unique effect of boredom and thus could have perpetuated the general belief that boredom is negative. Hence, in Study 2, we tested the effects of boredom manipulation on anger and frustration to ascertain the causal mechanism that underlies boredom and creativity.

\section{Method}

Sixty-one participants (30 in the control condition and 31 in the boredom condition) engaged in the same boredom vs. control condition on the bean task

TABLE 2

Boredom Condition Predicting Number of Ideas (Study 1)

\begin{tabular}{lrrrrr}
\hline & B & SE & $\boldsymbol{\beta}$ & $\boldsymbol{t}$ & $\boldsymbol{R}^{\mathbf{2}}$ \\
\hline Model 1 & & & & & \\
PA & 1.06 & .52 & .20 & $2.02^{*}$ & \\
NA & 1.24 & 1.06 & .12 & 1.18 & .05 \\
Model 2 & & & & & \\
$\quad$ Boredom condition & \\
PA & 3.99 & 1.46 & .28 & $2.73^{* *}$ & \\
NA & 1.50 & .53 & .28 & $2.82^{* *}$ & \\
& .68 & 1.05 & .06 & .65 & .12
\end{tabular}

${ }^{\text {a }} \mathbf{0}=$ Control condition, 1 = Boredom condition

${ }^{*} p<.05$

${ }^{* *} p<.01$
TABLE 3

Boredom Condition Predicting Uniqueness Ratings of Ideas (Study 1)

\begin{tabular}{lrrrrr}
\hline & B & SE & $\boldsymbol{\beta}$ & $\boldsymbol{t}$ & $\boldsymbol{R}^{\mathbf{2}}$ \\
\hline $\begin{array}{l}\text { Model 1 } \\
\text { PA }\end{array}$ & .03 & .09 & .03 & .29 & \\
NA & -.16 & .19 & -.09 & -.84 & .01 \\
Model 2 & & & & & \\
$\quad$ Boredom condition ${ }^{\mathrm{a}}$ & .66 & .27 & .26 & $2.41^{*}$ & \\
PA & .10 & .09 & .11 & 1.07 & \\
NA & -.25 & .19 & -.13 & -1.29 & .08 \\
\hline${ }^{\text {a }} 0=$ Control condition, $1=$ Boredom condition \\
$\quad{ }^{*} p<.05$
\end{tabular}

for 30 minutes. Right after the bean task, participants completed a boredom scale with four items: bored, dull, lethargic, and sluggish on a 5-point Likert scale ranging from 1 (Not at all) to 5 (Extremely) ( $\alpha=0.88$; Larsen \& Diener, 1992; Posner, Russell, \& Peterson, 2005). Anger/frustration were measured using two items (angry and frustrated) on a 5-point Likert scale ranging from 1 (Not at all) to 5 (Extremely) ( $\alpha=0.88$; Berkowitz, 1989; Chang, 2009) along with PA ( $\alpha=$ $0.89)$ and NA ( $\alpha=0.92)$ (PANAS; Watson et al., 1988).

\section{Results}

Participants in the boredom condition reported a significantly higher level of boredom $(M=3.74$, $\mathrm{SD}=0.76)$ than those in the control condition $(M=$ 2.08, $\mathrm{SD}=0.81), t(59)=8.21, p<.001,95$ percent confidence interval $=[1.25,2.06]$. However, anger levels for the boredom condition $(M=1.71$, SD $=$ $1.01)$ and the control condition $(M=1.50, \mathrm{SD}=0.82)$ were not significantly different, $t(59)=0.89, p=$ not significant, 95 percent $\mathrm{CI}=[-0.26,0.68]$. Frustration levels for the boredom condition $(M=1.96, \mathrm{SD}=1.04)$ and the control condition $(M=1.53, \mathrm{SD}=0.82)$ were also not significantly different, $t(59)=1.79, p=$ n.s., 95 percent CI $=[-0.05,0.91]$. Therefore, the boredom manipulation significantly increased the boredom felt by participants, but it did not significantly increase their anger or frustration. Participants in the boredom condition felt significantly lower positive activating affect $(M=2.33, \mathrm{SD}=0.69)$ than those in the control condition $(M=3.53, \mathrm{SD}=0.57), t(59)=-7.31, p<.001,95$ percent CI $=[-1.52,-0.86]$. Participants in the boredom condition did not feel significantly higher negative activating affect $(M=1.78, \mathrm{SD}=0.69)$ than those in the control condition $(M=1.57, \mathrm{SD}=0.61), t(59)=1.32$, $p=$ n.s., 95 percent $\mathrm{CI}=[-0.11,0.55]$.

\section{STUDY 3}

In Study 3, we made several changes based on the findings from Study 1. First, we included individual 
difference measures that could potentially help us understand the moderator-of-process on the boredom-creativity link (Baas et al., 2008). Accordingly, we included a diverse set of individual difference measures, including Big Five personality traits, goal orientation, LOC, NOC, and self-efficacy. Second, we improved our measure of creative performance to better align with organizational contexts. In contrast to Study 1, in which participants were told they would not be judged in terms of quality of ideas-and thus only strove to generate as many ideas as possible-Study 3 used a task that focused on the quality of ideas to better reflect actual creative performance in organizations (Zhou \& Shalley, 2010). Creative performance in organizations requires improvements in terms of how things are done and emphasizes generating ideas that are both unique and practical. Therefore, we used the INSITE! task, in which participants were asked to fulfill a hypothetical client's innovation needs and develop a new product with a strong focus on novelty and usability.

\section{Method}

Participants. One hundred fifty-nine undergraduate college students (79 in the experimental group and 80 in the control group) from a large university in Singapore (60.5 percent female; age range = 18-28; Chinese ethnicity $=76.8$ percent) participated in the study.

Procedure. On arrival in the laboratory, participants were seated in individual cubicles and told they would be engaging in three tasks randomly selected from a pool of tasks. Participants then filled out a set of individual difference measures (personality, goal orientation, NOC, and LOC). On completion of the survey, participants were asked to perform the bean task, as described in Study 1, for 30 minutes. Participants were then informed that they would be taking part in a product-development task for the next 5 minutes. Specifically, they were asked to imagine themselves as employees of a new product development team in a company called INSITE! (Kellogg Team and Group Center, 2001). Their goal was to come up with creative ideas for an easy, efficient, lightweight, and aesthetic mechanism that dog owners and dog walkers could use to clean up dog excrement while walking their dogs.

\section{Measures}

Manipulation check. Boredom was measured using four items (bored, sluggish, dull, and lethargic) on a 5-point Likert scale ranging from 1 (Not at all) to 5 (Extremely). Individuals in the boredom condition reported a significantly higher level of boredom $(M=$ $3.98, \mathrm{SD}=0.91)$ than individuals in the control condition $(M=2.44, \mathrm{SD}=1.14),(t(157)=9.14, p<$ .001).

Negative and positive mood. Each participant's negative and positive mood were measured using the Positive and Negative Affect Scale (PANAS; Watson et al., 1988).

Individual differences. Big Five personality traits were measured with the 44-item scale developed by John and Srivastava (1999). NOC was measured with nine items developed by Cacioppo, Petty, and Hogan (1982). Internal LOC was measured with 20 items developed by Levenson (1981). Goal orientation (i.e., LGO, performance goal orientation (PGO), and avoidance goal orientation (AGO)) was measured with the goal orientation scale developed by VandeWalle (1997). Self-efficacy was measured with the 8-item creative self-efficacy scale developed by Carmeli and Schaubroeck (2007). All individual difference measures were based on a 5-point Likert scale ranging from 1 (Strongly disagree) to 5 (Strongly agree) (See Table 4 for reliabilities.).

Creativity. Consistent with prior research, we defined creativity as the joint novelty and usefulness of ideas (Zhou \& Shalley, 2010). This means that creative ideas must be high in both novelty/ uniqueness and usefulness/practicality; ideas that are high on one dimension but low on another are not considered creative. For novelty, two independent coders who were blind to experimental conditions rated each individual's ideas on a 5-point Likert scale ranging from 1 (Not novel at all) to 5 (Very novel). The same coders coded the ideas' usefulness in a different order than that used for novelty on a 5-point scale ranging from 1 (Not useful at all) to 5 (Very useful). All four agreement and reliability measures achieved adequate levels of agreement and reliability (novelty: $r_{\mathrm{wg}}=0.88 ; \alpha=0.81 ; \mathrm{ICC}_{1}=0.59 ; \mathrm{ICC}_{2}=0.73$; usefulness: $r_{\mathrm{wg}}=0.89 ; \alpha=0.82 ; \mathrm{ICC}_{1}=0.61 ; \mathrm{ICC}_{2}=$ 0.74). We then multiplied novelty and usefulness scores to represent an individual's creative performance (Hoever, Van Knippenberg, Van Ginkel, \& Barkema, 2012; Zhou \& Oldham, 2001).

Number of ideas. The number of ideas individuals generated was counted at the end of the 5-min product development task.

\section{Result}

Table 4 presents the descriptive statistics, reliabilities, and correlations of the main variables in Study 3. Unlike the results from Study 1, which showed significant effects of the boredom condition and positive affective state on unique idea generation, we did not find any significant relationships between 


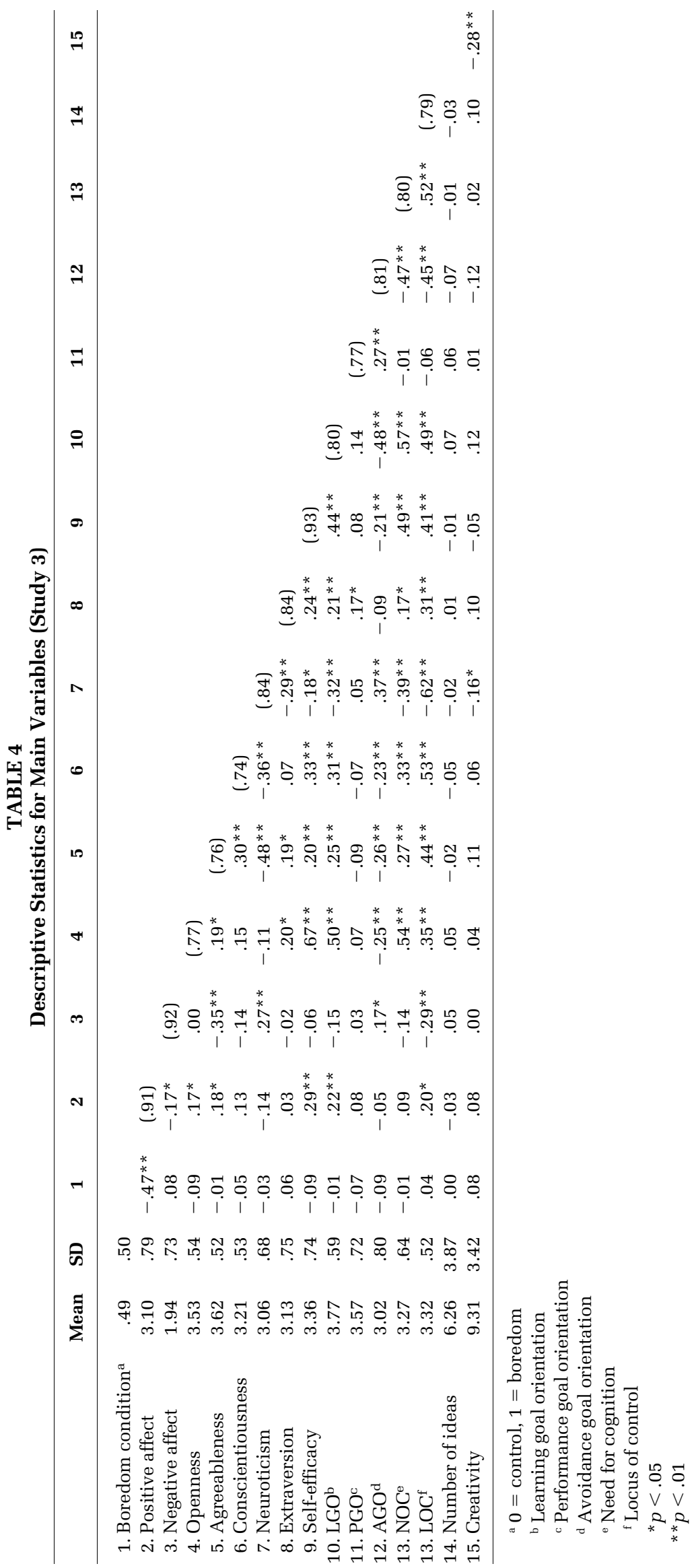


the boredom condition ( $r=0.08, p=$ n.s.), positive affect ( $r=0.08, p=$ n.s.) or negative affect $(r=.00$, $p=$ n.s.), and creativity. These results indicate that boredom might be related to creative performance in a more complex manner. Using hierarchical regression analysis, we tested the interaction effects of individual differences on the boredom-creativity link (Tables 5-8). At Step 1, we examined the main effects of positive and negative affect on creativity and found no significant effects of positive $(\beta=0.08$, $p=$ n.s.) or negative affect ( $\beta=0.01, p=$ n.s.) on creativity. At Step 2, we examined the main effects of the boredom condition and individual differences and found no significant main effects of either the boredom condition or individual differences. At Step 3, we entered the interaction effect of an individual difference and the boredom condition on creativity.

We found significant interaction effects of openness to experience, LGO, NOC, and internal LOC with the boredom condition in predicting creativity (Tables 5-8). Interaction patterns are depicted in Figures 1-4 and are consistent for all four individual difference variables. Specifically, under the boredom condition, individuals with higher levels of openness to experience, LGO, NOC, and internal LOC were more likely to produce creative ideas. The simple slopes of the boredom condition presented in Figures 1-4 were all significant (openness to experience: slope $=1.54, t=2.07, p<.05$; LGO: slope $=$ $1.66, t=2.54, p<.05$; NOC: slope $=1.24, t=1.96$, $p=.05$; LOC: slope $=2.46, t=3.58, p<.05$ ). This indicates that being bored benefited individuals with high openness to experience, high LGO, high NOC, and high internal LOC by improving their creative performance. We found no significant interaction effects between boredom and the rest of the individual difference variables (agreeableness, conscientiousness, neuroticism, extraversion, PGO, AGO, and selfefficacy).

TABLE 5

Boredom and Openness to Experience Predicting Creativity (Study 3)

\begin{tabular}{lrrrrr}
\hline & B & SE & $\boldsymbol{\beta}$ & $\boldsymbol{t}$ & $\boldsymbol{R}^{\mathbf{2}}$ \\
\hline Step 1 & & & & & \\
$\quad$ PA & .36 & .35 & .08 & 1.02 & \\
NA & .05 & .38 & .01 & .13 & .01 \\
Step 2 & & & & & \\
$\quad$ Boredom condition ${ }^{\mathrm{a}}$ & 1.03 & .62 & .15 & 1.66 & \\
$\quad$ Openness to experience & .17 & .51 & .03 & .32 & .03 \\
Step 3 & & & & & \\
$\quad$ Boredom $\times$ openness & 2.46 & 1.00 & 1.28 & $2.45^{*}$ & .06 \\
\hline${ }^{a} 0=$ Control condition, $1=$ boredom condition & & \\
$\quad{ }^{*} p<.05$
\end{tabular}

TABLE 6

Boredom and LGO Predicting Creativity (Study 3)

\begin{tabular}{|c|c|c|c|c|c|}
\hline & B & SE & $\boldsymbol{\beta}$ & $t$ & $R^{2}$ \\
\hline \multicolumn{6}{|l|}{ Step 1} \\
\hline PA & .36 & .35 & .08 & 1.02 & \\
\hline NA & .05 & .38 & .01 & .13 & .01 \\
\hline \multicolumn{6}{|l|}{ Step 2} \\
\hline Boredom condition ${ }^{\mathrm{a}}$ & .95 & .62 & .14 & 1.53 & \\
\hline Learning GO & .55 & .48 & .09 & 1.16 & .03 \\
\hline \multicolumn{6}{|l|}{ Step 3} \\
\hline Boredom $\times$ LGO & 1.89 & .91 & 1.07 & $2.08^{*}$ & .06 \\
\hline
\end{tabular}

\section{DISCUSSION}

Boredom is unpleasant, and if given a choice, people normally avoid it. Some even consider boredom to be as disturbing as pain, if not more. When Wilson et al. (2014) asked participants to either do nothing for 15 minutes or administer painful electric shocks to themselves, 43 percent of participants shocked themselves at least once. The discomfort associated with boredom is probably one of the reasons people often fail to see its potential benefits. We hope that our preliminary research has shed light on why being bored is not necessarily bad; instead, feeling bored could be associated with creativity.

The results of Study 1 provide preliminary evidence of a causal link between boredom and performance on a divergent task: Individuals who felt bored were more likely to come up with unique ideas than those who did not feel bored. This effect remained significant even after controlling for positive and negative moods. In Study 2, we demonstrated that our manipulation had distinctively increased boredom rather than inducing a significant increase in other negative activating emotions, such as anger and frustration. These results provide further support for the findings of Study 1 that boredom

TABLE 7

Boredom and NOC Predicting Creativity (Study 3)

\begin{tabular}{lrrrrr}
\hline & B & SE & $\boldsymbol{\beta}$ & $\boldsymbol{t}$ & $\boldsymbol{R}^{\mathbf{2}}$ \\
\hline Step 1 & & & & & \\
$\quad$ PA & .36 & .35 & .08 & 1.02 & \\
$\quad$ NA & .05 & .38 & .01 & .13 & .01 \\
Step 2 & & & & & \\
$\quad$ Boredom condition & \\
$\quad$ NOC & 1.02 & .62 & .15 & 1.65 & \\
$\quad$ Step 3 & .05 & .43 & .01 & .12 & .02 \\
$\quad$ Boredom $\times$ NOC & 1.89 & .85 & .93 & $2.23^{*}$ & .06 \\
\hline
\end{tabular}

${ }^{\mathrm{a}} \mathbf{0}=$ Control condition, 1 = boredom condition

${ }^{*} p<.05$ 
TABLE 8

Boredom and LOC Predicting Creativity (Study 3)

\begin{tabular}{lccccc}
\hline & B & SE & $\boldsymbol{\beta}$ & $\boldsymbol{t}$ & $\boldsymbol{R}^{\mathbf{2}}$ \\
\hline Step 1 & & & & & \\
$\quad$ PA & .36 & .35 & .08 & 1.02 & \\
$\quad$ NA & .05 & .38 & .01 & .13 & .01 \\
Step 2 & & & & & \\
$\quad$ Boredom condition & \\
$\quad$ LOC & .87 & .62 & .12 & 1.39 & \\
$\quad$ Step 3 & .85 & .56 & .13 & 1.52 & .04 \\
$\quad$ Boredom $\times$ LOC & 3.41 & 1.02 & 1.71 & $3.34^{* *}$ & .10 \\
\hline
\end{tabular}

Note. ${ }^{\text {a }} \mathbf{0}=$ Control condition, 1 = Boredom condition; ${ }^{* *} p<.01$

enhances one's creativity. This result corroborates previous findings that boredom can also lead to positive effects. For example, Hamilton, Haier, and Buschsbaum (1984) report that college students who felt bored performed significantly better on Guilford's divergenceseeking task. This likely seemed counterintuitive at the time, and the authors did not speculate as to why that was the case. We believe we are in a better position today to understand their findings. Likewise, in another study on understimulation-in which boredom was not considered-Baird, Smallwood, Mrazek, Kam, Franklin, and Schooler (2012) found that individuals who were engaged in an unstimulating task improved their performance on a subsequent creative task.

Using the moderator-in-process approach (Baas et al., 2008), Study 3 results suggest that when feeling bored, some individuals are more likely to engage in divergence-seeking and novelty-seeking processes than others, and these processes can trigger enhanced creativity. Not all bored individuals became more creative; a key factor is who they are. Specifically, individuals with high openness to experience, LGO, NOC, and internal LOC are more likely to come up with highly creative ideas in the boredom condition. What do these four differences have in common? It seems that they are all high in epistemic motivation, which

FIGURE 1

The Interaction Effect of Openness to Experience on Boredom and Creativity

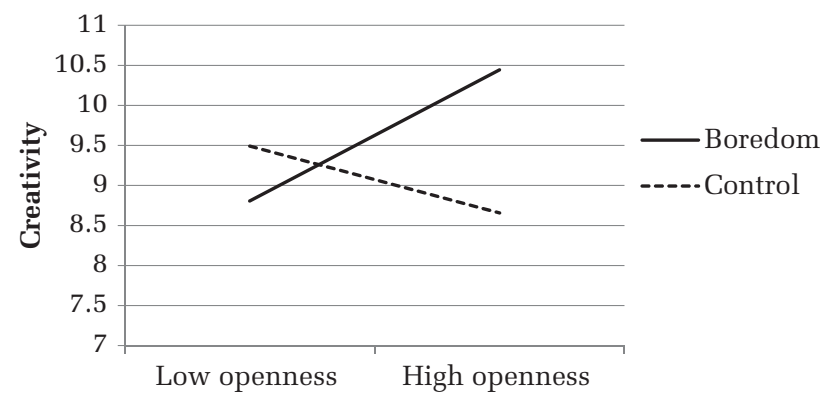

FIGURE 2

\section{The Interaction Effect of LGO on Boredom and Creativity}

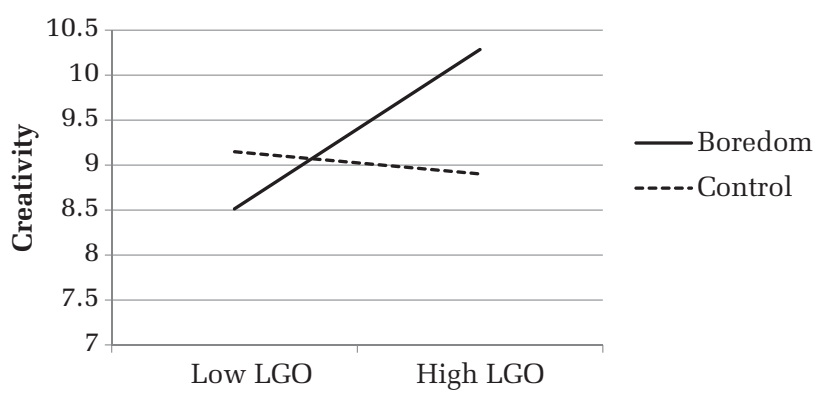

promotes the diversity and depth with which new information is searched for and processed (De Dreu, Nijstand, Bechtoldt, \& Baas, 2011). People who are high in these traits are known to be intrinsically inclined toward complex thinking, experimenting with new ideas, and engaging in cognitive exploration (Hirst, Van Knippenberg, \& Zhou, 2009; Madrid \& Patterson, 2016; Malik, Butt, \& Choi, 2015; Prabhu, Sutton, \& Sauser, 2008). On the other hand, conscientiousness or creative self-efficacy did not moderate the effects of boredom. The absence of any interaction effects between boredom and conscientiousness or PGO on creativity under boredom suggests that being selfdisciplined or achievement-driven does not facilitate the boredom-creativity link.

Our findings suggest boredom as a cause of divergence-seeking, exploratory tendencies. Other researchers concur with this divergence-triggering aspect of boredom. As an unpleasant emotion, boredom pushes people to change and do something different (Martin et al., 2006). As a low-arousal emotion, individuals seek to find something stimulating that involves variety and novelty (Faison, 1977). Boredom works as a push for change such that when individuals are bored, they are in a mode of searching for new stimuli, seeking challenges, and reaching out for changes and actions (Csikszentmihalyi, 1975). Elpidorou (2014) suggests that boredom is an indicator of intrinsic motive, by serving as a warning that individuals are not doing what they want to do, which could cause them to switch their goals or tasks. Last, Faison (1977) argues that boredom is the emotion that addresses individuals' drive for variety, whereby they seek changes and challenges in their activities. From an evolutionary

Author's voice:

If you were to do this study again, what would you do differently? 
FIGURE 3

The Interaction Effect of NOC on Boredom and Creativity

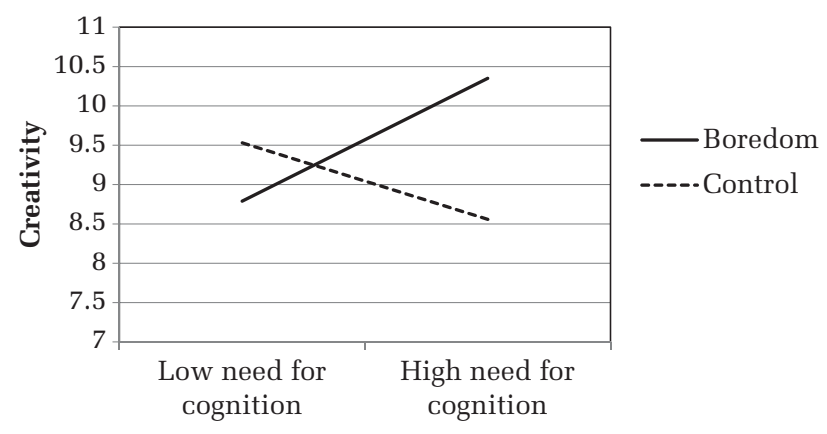

perspective, boredom may play an important role in survival and adaptation among living organisms. For example, signs of boredom are often noticeable in young animals, such as puppies and kittens; they are often observed engaging in constant play, by which they learn to develop the cognitive and physical capacities that are fundamental for survival in later stages of their lives (Fowler, 1965; Glanzer, 1958).

In a related vein, our results suggest that boredom acts as an impetus to search for and explore noveltyseeking behaviors. This process is similar to the cognitive dissonance phenomenon, although dissonance studies focus on inconsistency in cognitive and attitudinal aspects (Elliot \& Devine, 1994). Festinger (1957) argued that inconsistency in one's cognition (i.e., cognitive dissonance) brings about psychological discomfort, creates tension, and drives states like hunger, which in turn direct

\section{FIGURE 4}

The Interaction Effect of Internal LOC on Boredom and Creativity

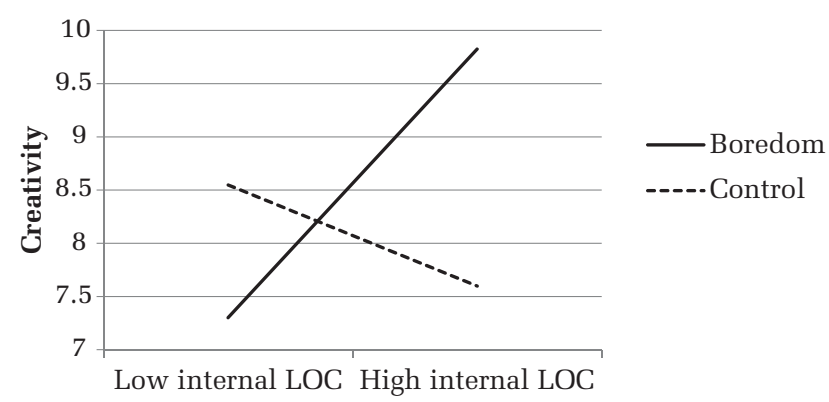

individuals to decrease tension through changes in their attitudes. In their cognitive dissonance perspective on guilt, Devine, Monteith, Zuwerink, and Elliot (1991) found that low-prejudice individuals are more likely to have a high and salient moral standard that renders them more susceptible to cognitive dissonance, and thereby exhibit prosocial and reparative behaviors. Similarly, in Study 3 , the experience of boredom only benefited those individuals who were predisposed to divergent thinking. We speculate that boredom may be particularly uncomfortable for individuals who enjoy engaging in intellectual activities, experimenting with complex ideas, and exploring different beliefs. Therefore, when bored, such individuals should engage their drive for intellectual pursuits and cognitive stimulation, and generate ideas that are high in both novelty and practicality.

\section{Boredom and Creativity}

In an organization, creativity means coming up with fresh or unique ideas for changing processes, products, or services to address the problem at hand (Amabile, Barsade, Mueller, \& Staw, 2005). Creativity is one of the key drivers of competitive advantage in today's business environment (Gong, Zhou, \& Chang, 2013); without it, nothing new can be produced. Individuals who are responsible for generating creative solutions must often go beyond-and frequently abandon-customary ways of doing things. Consistent with this view, previous studies have demonstrated that the crux of creativity is a novelty-seeking process in which individuals actively generate diverse and unique ideas or perspectives in their search for highly original solutions (Amabile, 1983; Amabile et al., 2005).

Previous studies on emotion and creativity have focused on activating emotions. For example, the dual-pathway model of creativity proposes that activation, which works as an energizer, is a precursor for creative processes (De Dreu et al., 2008). Activating positive mood states (e.g., elation and happiness) enhance creativity through cognitive flexibility by broadening the scope of attention and thought repertoires, whereas activating negative mood states (e.g., anger and anxiety) enhance creativity through cognitive effort and perseverance. While positive affect and creativity link is widely supported, empirical support for negative emotions and creativity has largely been inconsistent, implying a lack of generalized process that is responsible for negative emotions - creativity (Baas et al., 2008). Recognizing the complexity of negative affect, organizational scholars have called for more scrutiny of the influence of negative affect on creativity (Bledow, Rosing, \& Frese, 2013; George \& Zhou, 2007). 
Our research makes a unique contribution to the creativity literature by highlighting the commonly overlooked negative and deactivating affective state of boredom. In a carefully controlled laboratory setting with random assignment of participants, we were able to isolate the effect of boredom (a negative and deactivating emotion) on creativity from other potentially confounding and negative activating emotions. This addresses the need for studies that focus on specific negative emotions and creativity and identify the complex underlying mechanism (Baas et al., 2008). Perhaps the only thing that people in a negative mood have common is their desire to get out of that state (i.e., mood-as-feedback), and how they act on it depends on the specificity of emotion and who they are. Negative emotions typically evolve to manage fundamental and specific situational demands, and thereby trigger distinct, immediate, and targeted behavioral responses (Gasper, 2003; Lewis, Harviland-Jones, \& Barrett, 2008; Shalley, Zhou, \& Oldham, 2004).

For instance, anger typically evokes an approach-andfight response, whereas fear tends to elicit an avoidanceand-flight response. Our results imply that boredom can trigger cognitive processes that underlie creativity, such as heightened drive to engage in divergent thinking and novelty-seeking (Mayer, 1992). Boredom seems to prompt individuals to explore alternative solutions to problems or challenge the status quo; without the innate ability to experience boredom, human beings would be less compelled to move out of their comfort zones and seek different, and sometimes better, circumstances. Lacking this incentive, they could be less adaptive to ever-changing survival demands. This notion of creativity that arises from discomfort and tension is consistent with a dynamic and process view of innovation in organizations (West, 2002). Perhaps the inner tension created by boredom activates one's desire to explore and develop different novel strategies, some of which will give us an edge in survival or competition-and thus justify the important role boredom plays in our psychological repertoire.

\section{Practical Contributions}

In our daily lives, boredom could easily be masked by other negative emotions such as anger, frustration, and irritability. This may be why boredom is generally associated with negative effects in many correlational studies. However, inducing a mild and negative state of boredom can increase one's creativity. Our findings

Author's voice:

Was there anything that surprised you about the findings? suggest that boredom could potentially be an untapped source of human motivation, especially at work; furthermore, this latent energy could be harnessed by managers in a positive way to benefit their work teams and organizations as a whole. For example, when bored, some people choose to engage in activities that ultimately hamper their job performance, such as being overly engrossed in hobbies or occupying themselves with other means of entertainment (e.g., surfing the internet during work hours). If bored employees' desire for variety and novelty can be enhanced and shaped by their managers, having bored employees may not be entirely negative. Overall, this means that managers and organizations should be more nuanced in how they manage boredom in the work environment.

In addition, findings from Study 3 suggest that boredom is not helpful for everyone. Accordingly, better awareness of the nature of particular individual difference traits-specifically, as identified in this study, openness to experience, LGO, NOC, and internal LOC-would be helpful. By understanding their own traits, they could regulate their desired work performance from time to time by designating certain parts of the day "boredom periods." Interestingly, there is a growing trend among organizations, such as Google and Zappos, to create spaces for employees in which they can nap or spend time without disruption and, in turn, disconnect and get recharged (Henry, 2015). Given the potential positive effect of boredom highlighted by our study, it might be worthwhile to equip these areas with bowls of colored beans; their managers might be in for a pleasant surprise.

\section{Limitations and Future Research}

Although boredom enhanced the quantity and uniqueness of the ideas participants generated in Study 1, there was no main effect of boredom on creativity in Study 3. We speculate that the inconsistent results could be due to the use of different tasks that tapped into more or less of the divergenceseeking process. Specifically, in Study 1, the goal was to generate as many reasons as possible-with no expectations for the quality of ideas generated-and hence individuals may have felt less constrained and, in turn, that they could simply write down any ideas that came to mind. Creativity scholars have demonstrated that such an idea-generation task heavily depends on divergent thinking, by which the quantity of ideas is positively associated with the quality of ideas; that is, as the number of ideas increases, the uniqueness and uncommonness of these ideas increases (De Dreu et al., 2008; Diehl \& Stroebe, 1987; Osborn, 1953). Accordingly, in Study 1 there was a significant positive relationship between the quantity and uniqueness of ideas $(r=0.49 ; p<.01$; Table 1$)$. 
By contrast, in Study 3, the goal was to come up with solutions for a new product that meets a business client's needs. The product had to be both unique and practical, and thus clear standards for a good idea were present. While generating ideas under these conditions, individuals evaluate their ideas against the criteria, and therefore the task taps into both divergent thinking and a convergent selection process. For such creative tasks, there is a trade-off between the quantity and quality of ideas (Baas et al., 2008; Rietzschel, Nijstad, \& Stroebe, 2010). Consistent with this argument, in Study 3, we found a significant negative relationship between the number of ideas and the ideas' creativity ratings $(r=-0.28 ; p<$ .01 ; Table 4). Therefore, despite inconsistent main effects across the two creativity tasks, the results are consistent with our suggestion that boredom can trigger divergent, exploratory, and variety-seeking cognitive processes such that when those tasks relied heavily on divergent thinking, the positive effect of boredom on creativity was more pronounced.

While these studies identified boredom as an emotion with the potential to promote creativity, boredom is not to be interpreted as the only emotion relevant for exploratory and novelty-seeking behaviors. For example, interest is also an activating and positive emotion that has been suggested as a source of intrinsic motivation for learning and exploration (Silvia, 2008). When individuals feel a high level of interest, they are more likely to direct their attention and stay focused on the task (Sansone \& Thoman, 2005). Interest functions as an affective state that monitors individuals' self-regulation of motivation; we believe that interest and boredom could work in tandem and in a dynamic fashion to regulate a novelty-seeking mechanism. That is, boredom seems to trigger avoidance feedback systems, by which individuals move away from an undesired condition, such as repetitive or simple stimuli (i.e., a discrepancy-enlarging process). On the other hand, interest seems to trigger an approach feedback system when individuals move toward the desired condition, such as new or complex stimuli (i.e., a discrepancy-reducing process; Carver \& Scheier, 2001). Therefore, one's levels of boredom and interest serve as fundamental emotions to balance one's level of exploratory motives through a dynamic regulatory process of gravitational pull toward optimal stimulation and antigravitational push against understimulation.

\section{REFERENCES}

Amabile, T. M. 1983. The social psychology of creativity: A componential conceptualization. Journal of Personality and Social Psychology, 45: 357-376.
Amabile, T. M., Barsade, S. G., Mueller, J. S., \& Staw, B. M. 2005. Affect and creativity at work. Administrative Science Quarterly, 50: 367-403.

Baas, M., De Dreu, C. K. W., \& Nijstad, B. A. 2008. A metaanalysis of 25 years of mood-creativity research: Hedonic tone, activation, or regulatory focus? Psychological Bulletin, 134: 779-806.

Baird, B., Smallwood, J., Mrazek, M. D., Kam, J. W., Franklin, M. S., \& Schooler, J. W. 2012. Inspired by distraction mind wandering facilitates creative incubation . Psychological Science, 23: 1117-1122.

Baumeister, R. F. 1999. Evil: Inside human violence and cruelty. New York: Macmillan.

Baumeister, R. F., \& Campbell, W. K. 1999. The intrinsic appeal of evil: Sadism, sensational thrills, and threatened egotism. Personality and Social Psychology Review, 3: 210-221.

Berkowitz, L. 1989. Frustration-aggression hypothesis: Examination and reformulation. Psychological Bulletin, 106: 59-73.

Bledow, R., Rosing, K., \& Frese, M. 2013. A dynamic perspective on affect and creativity. Academy of Management Journal, 56: 432-450.

Brissett, D., \& Snow, R. P. 1993. Boredom: Where the future isn't. Symbolic Interaction, 16: 237-256.

Cacioppo, J., Petty, R., \& Hogan, R. 1982. The need for cognition. Journal of Personality and Social Psychology, 42: 116-131.

Carmeli, A., \& Schaubroeck, J. 2007. The influence of leaders' and other referents' normative expectations on individual involvement in creative work. The Leadership Quarterly, 18: 35-48.

Carver, C. S., \& Scheier, M. F. 2001. On the self-regulation of behavior. New York: Cambridge University Press.

Charlton, J., \& Hertz, R. 1989. Guarding against boredom: Security specialists in the US Air Force. Journal of Contemporary Ethnography, 18: 299-326.

Chang, M. 2009. An appraisal perspective of teacher burnout: Examining the emotional work of teachers. Educational Psychology Review, 21:193-218.

Chong, S. H., \& Park, G. 2017. The differential effects of incidental anger and sadness on goal regulation. Learning and Motivation, 58: 1-15.

Conrad, P. 1997. It's boring: Notes on the meanings of boredom in everyday life. Qualitative Sociology, 20: $465-475$.

Csikszentmihalyi, M. 1975. Beyond boredom and anxiety. San Francisco, CA: Jossey-Bass.

Cummings, M. L., Mastracchio, C., Thornburg, K. M., \& Mkrtchyan, A. 2013. Boredom and distraction in 
multiple unmanned vehicle supervisory control. Interacting with Computers, 25: 34-47.

De Dreu, C. K., Baas, M., \& Nijstad, B. A. 2008. Hedonic tone and activation level in the mood-creativity link: Toward a dual pathway to creativity model. Journal of Personality and Social Psychology, 94: 739-756.

De Dreu, C., Nijstad, B., Bechtoldt, M., \& Baas, M. 2011. Group creativity and innovation: A motivated information processing perspective. Psychology of Aesthetics, Creativity, and the Arts, 5: 81-89.

Devine, P., Monteith, M., Zuwerink, J., Elliot, A., \& Tesser, A. 1991. Prejudice with and without compunction. Journal of Personality and Social Psychology, 60: 817-830.

Diehl, M., \& Stroebe, W. 1987. Productivity loss in brainstorming groups: Toward the solution of a riddle. Journal of Personality and Social Psychology, 53: 497-509.

Elliot, A. J., \& Devine, P. G. 1994. On the motivational nature of cognitive dissonance: Dissonance as psychological discomfort. Journal of Personality and Social Psychology, 67: 382-394.

Elpidorou, A. 2014. The bright side of boredom. Frontiers in Psychology, 5: 1245.

Faison, E. W. 1977. The neglected variety drive: A useful concept for consumer behavior. Journal of Consumer Research, 4: 172-175.

Farmer, R., \& Sundberg, N. D. 1986. Boredom proneness-The development and correlates of a new scale. Journal of Personality Assessment, 50: 4-17.

Festinger, L. 1957. A theory of cognitive dissonance. New York: Wiley.

Fisher, C. D. 1993. Boredom at work: A neglected concept. Human Relations, 46: 395-417.

Fowler, H. 1965. Curiosity and exploratory behavior. New York: Macmillan.

Gasper, K. 2003. When necessity is the mother of invention: Mood and problem solving. Journal of Experimental Social Psychology, 39: 248-262.

Geiwitz, P. J. 1966. Structure of boredom. Journal of Personality and Social Psychology, 3: 592-600.

George, J., \& Zhou, J. 2002. Understanding when bad moods foster creativity and good ones don't: The role of context and clarity of feelings. Journal of Applied Psychology, 87: 687-697.

George, J., \& Zhou, J. 2007. Dual tuning in a supportive context: Joint contributions of positive mood, negative mood, and supervisory behaviors to employee creativity. The Academy of Management Journal, 50: 605-622.
The Economist. 2014. Dilbert at war: The stressful lives of the "chair force". The Economist. Retrieved from: http://www.economist.com/news/united-states/ 21604608-stressful-lives-chair-force-dilbert-war.

Glanzer, M. 1958. Curiosity, exploratory drive, and stimulus satiation. Psychological Bulletin, 55: 302.

Gong, Y., Zhou, J., \& Chang, S. 2013. Core knowledge employee creativity and firm performance: The moderating role of riskiness orientation, firm size, and realized absorptive capacity. Personnel Psychology, 66: 443-482.

Guglielmi, D., Simbula, S., Mazzetti, G., Tabanelli, M. C., \& Bonfiglioli, R. 2013. When the job is boring: The role of boredom in organizational contexts. Work, 45: 311-322.

Hackman, J. R., \& Oldham, G. R. 1976. Motivation through the design of work: Test of a theory. Organizational Behavior and Human Performance, 16: 250-279.

Hamilton, J. A., Haier, R. J., \& Buchsbaum, M. S. 1984. Intrinsic enjoyment and boredom coping scales: Validation with personality, evoked potential and attention measures. Personality and Individual Differences, 5: 183-193.

Henry, Z. 2015. 6 Companies (including Uber) where it's ok to nap. Retrieved from: https://www.inc.com/zoehenry/google-uber-and-other-companies-where-you-cannap-at-the-office.html.

Hirst, G., Van Knippenberg, D., \& Zhou, J. 2009. A crosslevel perspective on employee creativity: Goal orientation, team learning behavior, and individual creativity. The Academy of Management Journal, 52: 280-293.

Hoever, I., Van Knippenberg, D., Van Ginkel, W., \& Barkema, H. 2012. Fostering team creativity: Perspective taking as key to unlocking diversity's potential. Journal of Applied Psychology, 97: 982-996.

Isen, A. M., \& Baron, R. A. 1991. Positive affect as a factor in organizational behavior. Research in Organizational Behavior, 13: 1-53.

John, O. P., \& Srivastava, S. 1999. The big-five trait taxonomy: History, measurement, and theoretical perspectives. In L. A. Pervin \& O. P. John (Eds.), Handbook of personality: Theory and research, vol. 2: 102-138. New York: Guilford Press.

Joireman, J., Anderson, J., \& Strathman, A. 2003. The aggression paradox: Understanding links among aggression, sensation seeking, and the consideration of future consequences. Journal of Personality and Social Psychology, 84: 1287-1302.

Kass, S. J., Vodanovich, S. J., \& Callender, A. 2001. Statetrait boredom: Relationship to absenteeism, tenure, and job satisfaction. Journal of Business and Psychology, 16: 317-327. 
Katz, S. B. 1988. Seduction of crime: Moral and sensual attractions in doing evil. New York: Basic Books.

Larsen, R. J., \& Diener, E. 1992. Promises and problems with the circumplex model of emotion. Review of Personality and Social Psychology, 13: 25-59.

Levenson, H. 1981. Differentiating among internality, powerful others, and chance. In H. M. Lefcourt (Ed.), Research with the locus of control construct, vol. 1: 15-63. New York: Academic Press.

Lewin, K. 1951. Field theory in social science. New York: Harper \& Row.

Lewis, M., Hariland-Jones, J. M., \& Barrett, L. F. 2008. Handbook of emotions. New York: Guilford Press.

Madrid, H. P., \& Patterson, M. G. 2016. Creativity at work as a joint function between openness to experience, need for cognition and organizational fairness. Learning and Individual Differences, 51: 409-416.

Malik, M., Butt, A., \& Choi, J. 2015. Rewards and employee creative performance: Moderating effects of creative self-efficacy, reward importance, and locus of control. Journal of Organizational Behavior, 36: $59-74$.

Martin, M., Sadlo, G., \& Stew, G. 2006. The phenomenon of boredom. Qualitative Research in Psychology, 3: 193-211.

Mayer, R. E. 1992. Thinking, problem solving, cognition. New York: Freeman.

Mikulas, W. L., \& Vodanovich, S. J. 1993. The essence of boredom. The Psychological Record, 43: 3-12.

Nett, U. E., Goetz, T., \& Daniels, L. M. 2010. What to do when feeling bored? Students' strategies for coping with boredom. Learning and Individual Differences, 20: 626-638.

Osborn, A. F. 1953. Applied imagination. New York: Scribner.

Pekrun, R., Goetz, T., Daniels, L. M., Stupnisky, R. H., \& Perry, R. P. 2010. Boredom in achievement settings: Exploring control-value antecedents and performance outcomes of a neglected emotion. Journal of Educational Psychology, 102: 531-549.

Posner, J., Russell, J. A., \& Peterson, B. S. 2005. The circumplex model of affect: An integrative approach to affective neuroscience, cognitive development, and psychopathology. Development and psychopathology, 17: 715-734.

Prabhu, V., Sutton, C., \& Sauser, W. 2008. Creativity and certain personality traits: Understanding the mediating effect of intrinsic motivation. Creativity Research Journal, 20: 53-66.

Rietzschel, E., Nijstad, B., \& Stroebe, W. 2010. The selection of creative ideas after individual idea generation:
Choosing between creativity and impact. British Journal of Psychology, 101: 47-68.

Sansone, C., \& Thoman, D. B. 2005. Does what we feel affect what we learn? Some answers and new questions. Learning and Instruction, 15: 507-515.

Sansone, C., Weir, C., Harpster, L., \& Morgan, C. 1992. Once a boring task always a boring task? Interest as a selfregulatory mechanism. Journal of Personality and Social Psychology, 63: 379-390.

Schultz, D. P. 1964. Spontaneous alternation behavior in humans: Implications for psychological research. Psychological Bulletin, 62: 394-400.

Shalley, C. E., Zhou, J., \& Oldham, G. R. 2004. The effects of personal and contextual characteristics on creativity: Where should we go from here? Journal of Management, 30: 933-958.

Silvia, P. J. 2008. Interest-The curious emotion. Current Directions in Psychological Science, 17: 57-60.

Suedfeld, P. 1975. The benefits of boredom: Sensory deprivation reconsidered: The effects of a monotonous environment are not always negative; sometimes sensory deprivation has high utility. American Scientist, 63: 60-69.

Van Hooff, M. L. M., \& van Hooft, E. A. J. 2017. Boredom at work: Toward a dynamic spillover model of need satisfaction, work motivation, and work-related boredom. European Journal of Work and Organizational Psychology, 26: 133-148.

Van Kleef, G. A., Anastasopoulou, C., \& Nijstad, B. A. 2010. Can expressions of anger enhance creativity? A test of the emotions as social information (EASI) model. Journal of Experimental Social Psychology, 46: 1042-1048.

Van Tilburg, W. A., \& Igou, E. R. 2011. On boredom and social identity: A pragmatic meaning-regulation approach. Personality and Social Psychology Bulletin, 37: 1679-1691.

VandeWalle, D. 1997. Development and validation of a work domain goal orientation instrument. Educational and Psychological Measurement, 57: 995-1015.

Wallbott, H. G. 1998. Bodily expression of emotion. European Journal of Social Psychology, 28: 879-896.

Watson, D., Clark, L. A., \& Tellegen, A. 1988. Development and validation of brief measures of positive and negative affect: The PANAS scales. Journal of Personality and Social Psychology, 54: 1063-1070.

West, M. 2002. Sparkling fountains or stagnant ponds: An integrative model of creativity and innovation implementation in work groups. Applied Psychology, 51: 355-387.

Wiesner, M., Windle, M., \& Freeman, A. 2005. Work stress, substance use, and depression among young adult 
workers: An examination of main and moderator effect model. Journal of Occupational Health Psychology, 10: 83-96.

Wilson, T. D., Reinhard, D. A., Westgate, E. C., Gilbert, D. T., Ellerbeck, N., Hahn, C., Brown, C. L., \& Shaked, A. 2014. Just think: The challenges of the disengaged mind. Science, 345(6192): 75-77.

Zhou, J., \& Shalley, C. E. 2010. Deepening our understanding of creativity in the workplace: A review of different approaches to creativity research. In S. Zedeck (Ed.), APA handbook of industrial and organizational psychology, vol. 1: 275-302. Washington, DC: American Psychological Association.

Zhou, J., \& Oldham, G. R. 2001. Enhancing creative performance: Effects of expected developmental assessment strategies and creative personality. Journal of Creative Behavior, 35: 151-67.
Guihyun Park (guihyun.park@anu.edu.au) is a senior lecturer in Research School of Management at Australian National University. She received a $\mathrm{PhD}$ in organizational psychology from Michigan State University. Her research examines team information processing, emotions, and team creativity. Her interest in the effects of boredom was inspired by her son and her dog.

Beng-Chong Lim (bclim@ntu.edu.sg) is an associate professor in Nanyang Business School at Nanyang Technological University, Singapore. His research interests include leadership and team effectiveness, boredom and creativity, and societal impact of using drones in an urban environment.

Hui Si Oh (huisi.oh.2016@phdps.smu.edu.s.g) is a psychology doctoral candidate in the School of Social Sciences at Singapore Management University. She examines how having a paradoxical mindset, optimistic personality, and different social situations, such as being excluded or feeling bored, could influence teams' creative performance. 